\title{
Corrigendum
}

\section{Corrigendum to "Using pneumococcal and rotavirus surveillance in vaccine decision-making: A series of case studies in Bangladesh, Armenia and the Gambia" [Vaccine 36 (2018) 4939-4943]}

\author{
Alvira Z. Hasan ${ }^{\text {a,* }}$, Senjuti Saha ${ }^{\text {b }}$, Samir K. Saha ${ }^{\text {b,c }}$, Gayane Sahakyan ${ }^{\text {d }}$, Svetlana Grigoryan ${ }^{\text {e }}$, \\ Jason M. Mwenda ${ }^{\mathrm{f}}$, Martin Antonio ${ }^{\mathrm{g}}$, Maria D. Knoll ${ }^{\mathrm{h}}$, Tomoka Nakamura ${ }^{\mathrm{a}}$, Fatima Serhan ${ }^{\mathrm{a}}$, \\ Adam L. Cohen ${ }^{\mathrm{a}}$, for the Pneumococcal and rotavirus surveillance case study group \\ a Expanded Programme on Immunization (EPI), Department of Immunizations, Vaccines and Biologicals (IVB), World Health Organization, Geneva, Switzerland \\ ${ }^{\mathrm{b}}$ Child Health Research Foundation, Dhaka Shishu Hospital, Dhaka, Bangladesh \\ ${ }^{\mathrm{c}}$ Bangladesh Institute of Child Health, Dhaka Shishu Hospital, Dhaka, Bangladesh \\ ${ }^{\mathrm{d}}$ National Immunization Program, Armenia National Center of Disease Control and Prevention, Armenia \& Ministry of Health of the Republic of Armenia, Yerevan, Armenia

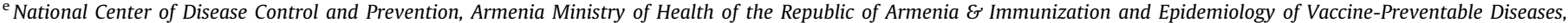 \\ Yerevan, Armenia \\ ${ }^{\mathrm{f}}$ The World Health Organization, Regional Office for Africa, Brazzaville, Congo \\ ${ }^{\mathrm{g}}$ Vaccines and Immunity Theme, Medical Research Council Unit, Fajara, Gambia \\ ${ }^{\mathrm{h}}$ Department of International Health, Johns Hopkins University, Baltimore, MD, United States
}

The authors regret that Tomoka Nakamura, Expanded Programme on Immunization (EPI), Department of Immunizations, Vaccines and Biologicals (IVB), World Health Organization, Geneva, Switzerland, was inadvertently left off as an author of this manuscript is updated as above.
The authors would like to apologise for any inconvenience caused.

DOI of original article: https://doi.org/10.1016/j.vaccine.2018.06.001

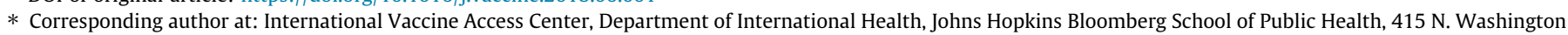
Street, \#564, Baltimore, MD 21231, USA.

E-mail address: ahasan7@jhmi.edu (A.Z. Hasan).

${ }^{1}$ Current address: Education Department, Liverpool School of Tropical Medicine, Pembroke Place, Liverpool L3 5QA, United Kingdom. 